\title{
Are the non-stationarities in global market shares of top automotive nations of the world same?
}

\author{
Huu Tran Ai ${ }^{1}$, Muhammad Imtiaz Subhani ${ }^{2}$, and Sommaya Prachyangprecha, ${ }^{3, *}$ \\ ${ }^{1}$ Van Hien University, Ho Chí Minh, Vietnam \\ ${ }^{2}$ ILMA University, Karachi, Pakistan \\ ${ }^{3}$ Suan Sunandha Rajabhat University, Bangkok, Thailand
}

\begin{abstract}
This paper is an attempt to investigate the non-stationary process in the global market shares of automotive industry of top 26 automotive producing nations. The time series data of global automotive market shares of top 26 automotive producing nations were collected from data stream Eikon for the period from 2002 to 2014. Augmented Dickey Fuller Unit root test (ADF URT) is used to investigate the nonstationarities or shocks in the outlined series of global automotive market shares. Findings confirmed the presence of shocks or non-stationarity (absence of stationary process) in global market shares of almost all top automotive producing nations except of Australia, India, Malaysia and South Africa for 2002 to 2014 . Findings further revealed that the nonstationarities got fixed at 2 nd difference in all outlined series of global market shares of automotive for the period from 2002 to 2014. It is also revealed that there are the same shocking patterns in the global market shares of all top automotive producing nations with few exception.
\end{abstract}

\section{Introduction}

For the human kind, the automobile industry is an emblem of technological phenomenon. It is one of the growing and greatest industries in the world. Its expansion is seen through competition, consumer demand and product life cycle. The specifications, which translates the growth of this industry lies with the consumer demands of vehicle safety, design, safety and comfort.

The industry also has gone through various global acquisitions /mergers and production outsourcing and relocation centres for developing economies with a shocking patterns of market shares [1,2].

The primary objective of this paper is to investigate the common non-stationary processes in the global market shares of automotive industry of top 26 automotive producing nations.

Augmented Dickey Fuller Unit root test (ADF URT) is used to investigate the nonstationarities or shocks in the outlined series of global automotive market shares.

\footnotetext{
*Corresponding authors: sommaya.pr@ssru.ac.th
} 
ADF unit root test is widely became so popular over the period of time to check the stationarity/nonstationary in the given time series as confirmed by [3].

\section{Literature Review}

Global market share is normally measured by the sales of a particular nation to total sales of world $[4,5]$. The same philosophy is used to measure the global market share of automotive of all top outlined automotive producing nations. It is important to cite that the market shares of small vehicles are increasing with a shocking patterns day by day and there are chances of an increase of market shares of these vehicles purchase from 47\% (year 2014) to $61 \%$ (year 2021). Hence, Overall sales and market share of the auto industry would scale up to $3.6 \%$ (690, 724 units) [6].

Mazda auto brand has been emerged to gain sales in year 2015 in the foreign automobile market It has launched new vehicles in the same year only. After Mazda, Toyota takes the market space in a way that their sales stay nominal. Internationally, it has also focused on its existing brands besides Camry model. Furthermore, the international brands are resumed operating to sell their auto brands in the local markets $[7,8]$.

\section{Research Methodology}

\subsection{Description of selected Variables, Data and Hypotheses}

As mentioned earlier that the main focus of this paper is to interrogate the non-stationary processes in the global market shares of automotive industry of top 26 automotive producing nations while further to find the similarities in the non-stationary processes in the outlined series. Therefore, the time series data of market shares of automotive industry of top 26 automotive producing nations are collected from data stream Eikon for the period from 2002 to 2014 . The top 26 automotive producing nations taken in this study are mentioned in the following table.

Table 1. Top 26 automotive producing nations.

\begin{tabular}{|l|l|l|l|}
\hline 1: Argentina & 8: Germany & 15: Mexico & 22: Taiwan \\
\hline 2: Australia & 9: Hungary & 16: Poland & 23: Turkey \\
\hline 3: Brazil & 10: India & 17: Romania & 24: Ukraine \\
\hline 4: Canada & 11: Indonesia & 18: Russia & 25: United Kingdom \\
\hline 5: China & 12: Italy & 19: South Africa & 26: United States \\
\hline 6: Czech Republic & 13: Japan & 20: South Korea & \\
\hline 7: France & 14: Malaysia & 21: Spain & \\
\hline
\end{tabular}

\subsection{Hypotheses established}

The following statement of hypothesis is established and tested for all outlined top 26 automotive producing nations. Statement of Hypothesis: Are the non-stationarities in global market shares of top automotive nations of the world same?

\subsection{Description of the econometric model deployed to test hypothesis}

The test which widely became so popular over the period of time to check the stationarity/ nonstationary in the given time series is ADF unit root test as confirmed by $[3,9,10]$. In order to see the presence of non-stationarity/ shocks and Unit root/ permanent shocks in 
data streams (for the period from 2002-2014) of market share of automotive industry, Augmented Dicky Fuller (ADF) model was deployed via ADF unit root test $[11,12]$. The ADF model is described below at level for explaining the stationary/ non-stationary process in the time series market share of automotive industry of outline top 26 automotive producing nations.

$$
\begin{aligned}
\Delta \text { Marketshares }_{t} & \\
& =\alpha y_{t-1}+x^{\prime}{ }_{t}+b_{2} \Delta \text { Marketshares }_{t-1}-- \\
& --b_{n} \Delta \text { Marketshares } \text { t }_{t-n}+E T_{t}
\end{aligned}
$$

\section{Findings and Results}

Table 2. Non-Stationarities and Similarity in the Non-Stationarities for Automotive global market

\begin{tabular}{|c|c|c|c|c|}
\hline \multicolumn{5}{|c|}{$\begin{array}{l}\text { P2: Are the shocks in automotive (Cars) total market shares of the world (top automotive } \\
\text { manufacturing countries) same? }\end{array}$} \\
\hline \multicolumn{5}{|c|}{$\begin{array}{l}\text { Statement of Hypothesis: There is the Non- Stationarity in the of total market shares of } \\
\text { automotive (cars) of top automotive manufacturing countries. }\end{array}$} \\
\hline & \multicolumn{2}{|c|}{ At Level } & \multicolumn{2}{|c|}{ Second Difference } \\
\hline & Prob. & Non-Stationary & Prob. & Non-Stationary \\
\hline H1: Argentina & 0.1712 & Yes/Failed to Reject & 0.0023 & No/Failed to Accept \\
\hline H2: Australia & 0.0355 & No & & \\
\hline H3: Brazil & 0.7645 & Yes/Failed to Reject & 0.0173 & No/Failed to Accept \\
\hline H4: Canada & 0.2023 & Yes/Failed to Reject & 0.0032 & $\mathrm{No} /$ Failed to Accept \\
\hline H5: China & 0.7718 & Yes/Failed to Reject & 0.0431 & $\mathrm{No} /$ Failed to Accept \\
\hline $\begin{array}{l}\text { H6: Czech } \\
\text { Republic }\end{array}$ & 0.2144 & Yes/Failed to Reject & 0.0019 & No/Failed to Accept \\
\hline H7: France & 0.2975 & Yes/Failed to Reject & 0.008 & No/Failed to Accept \\
\hline H8: Germany & 0.4172 & Yes/Failed to Reject & 0.0058 & No/Failed to Accept \\
\hline H9: Hungary & 0.3175 & Yes/Failed to Reject & 0.0036 & No/Failed to Accept \\
\hline H10: India & 0.0392 & No & & \\
\hline H11: Indonesia & 0.8088 & Yes/Failed to Reject & 0 & No/Failed to Accept \\
\hline H12: Italy & 0.2344 & Yes/Failed to Reject & 0.0022 & No/Failed to Accept \\
\hline H13: Japan & 0.4842 & Yes/Failed to Reject & 0.0232 & No/Failed to Accept \\
\hline H14: Malaysia & 0.0404 & No & & \\
\hline H15: Mexico & 0.6161 & Yes/Failed to Reject & 0.0048 & No/Failed to Accept \\
\hline H16: Poland & 0.1374 & Yes/Failed to Reject & 0.0027 & No/Failed to Accept \\
\hline H17: Romania & 0.4087 & Yes/Failed to Reject & 0.017 & No/Failed to Accept \\
\hline H18: Russia & 0.1991 & Yes/Failed to Reject & 0.0211 & No/Failed to Accept \\
\hline $\begin{array}{l}\text { H19: South } \\
\text { Africa }\end{array}$ & 0.0369 & No & & \\
\hline $\begin{array}{l}\text { H20: South } \\
\text { Korea }\end{array}$ & 0.2096 & Yes/Failed to Reject & 0.0038 & No/Failed to Accept \\
\hline H21: Spain & 0.4087 & Yes/Failed to Reject & 0.0170 & No/Failed to Accept \\
\hline H22: Taiwan & 0.639 & Yes/Failed to Reject & 0.0000 & No/Failed to Accept \\
\hline H23: Turkey & 0.2144 & Yes/Failed to Reject & 0.0019 & No/Failed to Accept \\
\hline H24: Ukraine & 0.3175 & Yes/Failed to Reject & 0.0036 & No/Failed to Accept \\
\hline $\begin{array}{l}\text { H25: United } \\
\text { Kingdom }\end{array}$ & 0.1991 & Yes/Failed to Reject & 0.0211 & No/Failed to Accept \\
\hline $\begin{array}{l}\text { H26: United } \\
\text { States }\end{array}$ & 0.7986 & Yes/Failed to Reject & 0.0160 & No/Failed to Accept \\
\hline
\end{tabular}
shares. 
Findings as shown in table 2 confirms the presence of non-stationarity (absence of stationary process) in global market shares of automotive for the selectedperiod for almost all mentioned nations except of Australia, India, Malaysia and South Africa [13]. Thus we are failed to reject hypothesis for almost all nations except of few. Further, the nonstationarities got fixed at 2 nd difference in the outlined series of global market shares of automotive for 2002 to 2014 . Therefore we are failed to accept stated hypothesis for all top automotive producing nations at 2 nd difference.

\section{Discussions and Conclusion}

The proposition of this research i.e. Are the shocks in the automotiveglobal market shares of the world same?, was investigated and the findings revealed and concluded that there is more or less same shocking patterns of automotive market shares of all outlined topautomotive manufacturing nations at level, and further the shocking patterns at 2nd difference were not found present in the outlined series of outlined countries for outlined period. Hence, the patterns of non-stationary and stationary processes are same for all top 26 automotive producing nations for the series of automotive global market shares.

\section{References}

1. A. Copeland et al., Working Paper 11257, NBER (2005)

2. D.N. Gujarati et al., Basic Econometrics (Tata McGraw-Hill Education private Ltd., New Delhi, 2009)

3. M.M. Ihnatenko et al., International J. of Economics and Business Administration 7(2), 290-301 (2019)

4. G. Maddala, K. Lahiri, Introduction to Econometrics (Wiley, 2011)

5. B. Nag et al., Working Paper Series 37 (2007)

6. M.I. Ermilova et al., Opcion 34(17), 1074-1087 (2018)

7. M. Scott et al., Southern Economic Journal 64(4), 973-986 (1998)

8. J.J. Tan, Proton, Perodua to regain market share this year? (2015) http://paultan.org/2015/02/25/proton-perodua-market-share-recover/

9. O. Sivash et al., IOP Conference Series: Earth and Environmental Science 272(3), 032118 (2019)

10. A.H. Tran et al., International J. of Recent Technology and Engineering $8(\mathbf{2 . 1 1})$, 3883-3888 (2019)

11. H.L.T. Mai et al., International J. of Recent Technology and Engineering 8(2.11), 3876-3882 (2019)

12. O.V. Takhumova et al., J. of Applied Economic Sciences 13(7), 1939-1944 (2018)

13. O.V. Zakharchenko et al., J. of Reviews on Global Economics 8, 859-872 (2019) 